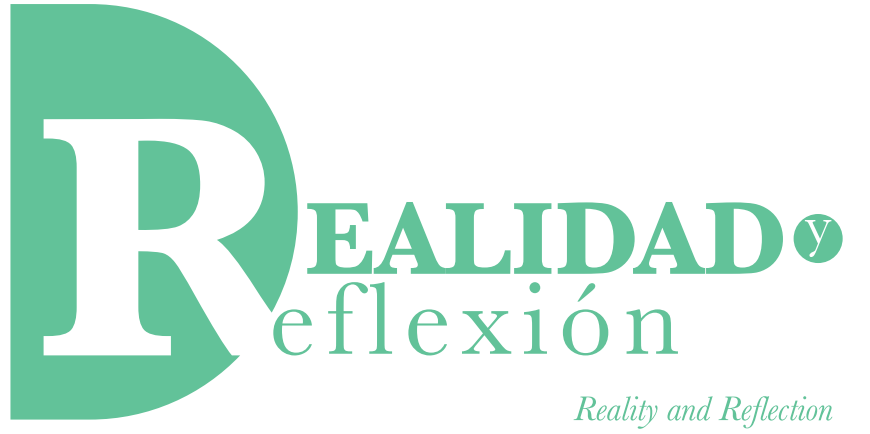

ISSN 1992-6510

e-ISSN 2520-9299

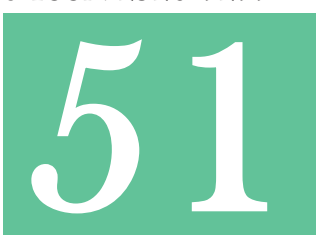

Año 20, N 51, San Salvador, El Salvador, Centroamérica. Revista Semestral Enero-Junio 2020

YEAR 20, $N^{\circ}$ 51, SAN SALVADOR, EL SALVADOR, CENTRAL AMERICA. SEMESTRAL JOURNAL JANUARY-JuNE 2020

\title{
Contenido de proteína, hierro y zinc en maíces criollos salvadoreños
}

Protein, iron and zinc content in salvadorian native maize

Manuel de Jesús Cortez Azenón Investigador independiente. Escuela Nacional de Agricultura "Roberto Quiñónez" Ingeniero Agrónomo por la Universidad Técnica Latinoamericana. azenoncortez@yahoo.com

Carlos Ayala Durán Universidade Federal do Rio Grande do Sul. Doctor en Desarrollo Rural por la Facultad de Ciencias Económicas de la Universidade Federal do Rio Grande do Sul. Porto Alegre, Brasil carlos.ayala@ufrgs.br

Fecha de recepción: 2 de octubre de 2019 Fecha aprobación: 6 de mayo de 2020 DOI: $10.5377 /$ ryr.v51i0.9842 


\section{RESUMEN}

Se evidencia que existe en El Salvador estudios sobre fitomejoramiento de maíz que priorizan usualmente la investigación de maíces híbridos, dejando de lado variedades de polinización libre y criollas. Asimismo, numerosas investigaciones suelen centrarse generalmente en aspectos productivos de este cereal. Ante esta tendencia, el presente texto realiza un análisis de aspectos nutricionales de maíces criollos salvadoreños. Para ello, se realiza un análisis bromatológico mediante el método de fluorescencia de rayos $\mathrm{X}$, identificando el porcentaje de proteína, el contenido de hierro y de zinc en seis maíces criollos salvadoreños y un testigo híbrido comercial. Los resultados muestran que los maíces criollos presentan en términos generales índices nutricionales similares y en algunos casos superiores al híbrido. Con ello, el testigo comercial no registra un desempeño superior en ninguno de los tres nutrientes evaluados, mostrando el peor índice en contenido de hierro y el penúltimo peor en contenido de zinc y porcentaje de proteína.

Palabras clave: El Salvador, Hierro, maíz, proteína, zinc.

\section{ABSTRACT}

Breading research regarding maize usually focuses in hybrid varieties in El Salvador, leaving aside native seed research. Likewise, numerous research papers usually focus on output results. Given this tendency, the present text performs a nutritional analysis of selected native maize in El Salvador. To do so, a bromatological analysis was implemented using the $x$ ray fuorescence method to identify the percentage of protein, zinc and iron content in six creole (native) varieties in El Salvador, as well as a commercial witness. Results show that native maize present similar and often higher nutrient content compared to the commercial witness. Hence, the comercial witness did not show superior performance in any of the three analyzed nutrients, having the worst iron content and second worst indicators in zinc and protein.

Keywords: El Salvador, iron, protein, maize, zinc. 


\section{Introducción}

El maíz ha jugado históricamente un papel fundamental en la llamada región mesoamericana. Existen estimaciones que datan a la domesticación del maíz hace 9000 años antes del presente (Mazoyer y Roudart, 2010). Siendo así, explicar el devenir de importantes civilizaciones imbricadas en la llamada región mesoamericana pasa necesariamente por comprender el surgimiento y desarrollo del cultivo del maíz.

En el caso específico de El Salvador, el maíz también ha tenido una importancia fundamental. La cultura de este cereal; por ejemplo, ha estado presente a lo largo de toda la historia de los diferentes sistemas agrarios al norte del departamento de La Libertad (Ayala y Miguel, 2016). ${ }^{1}$ Esta prominencia del maíz se ve patente a nivel del consumo ya que, a en todo el territorio nacional, se calcula que los salvadoreños consumen, en media, $80.81 \mathrm{~kg} / \mathrm{año}$ de maíz por persona en la zona urbana; y $127 \mathrm{~kg} /$ año para la zona rural (CENTA, 2008).

Como en el resto de Mesoamérica, el maíz es consumido en E1 Salvador en forma de tamales, atoles, riguas, etc. Pese a ello, la forma más común de consumirlo es mediante la tortilla de maíz nixtamalizada. En este sentido, Menchú y Meléndez (2011) retrataban que el 94\% de las familias sujetas a su investigación habían consumido tortilla de maíz en la última semana. Resultados similares son reportados por Ayala Durán (2018) a nivel municipal.

Si bien la importancia del maíz es patente en la realidad salvadoreña, los temas relacionados a la producción y consumo del mismo suelen centrarse básicamente en la esfera productiva, fomentando el mayor rendimiento posible del maíz por unidad de tierra. En ese sentido, factores claves para la seguridad alimentaria como el acceso a la alimentación adecuada y saludable o aspectos sobre salud y nutrición; suelen poseer papeles residuales en políticas públicas e investigaciones socio agrarias. ${ }^{2}$

Pese a ello, uno de los temas que está ganando atención dentro de los estudios en relación con el maíz es el tema nutricional. Con ello, aspectos relativos a la seguridad alimenticia y nutricional comienzan a tomar cada vez más fuerza en $\mathrm{El}$ Salvador. ${ }^{3}$ Uno de los aspectos enmarcados en esa temática es el valor nutricional de los diferentes tipos de maíz en el país. Con ello, se está poniendo cada vez mayor atención en la cantidad de proteína presente en los diferentes maíces; a la presencia, cantidad y calidad de aminoácidos, así como la existencia de otros micro y macronutrientes. De esta forma, órganos públicos salvadoreños han trabajado desde hace algunos años en el fitomejoramiento del maíz, particularmente referido al aumento de la proteína de este cereal. Sin embargo, estas investigaciones suelen centrarse en maíces híbridos (CENTA, 2002, 2008; 2008b, 2016), que son vistos como mejores alternativas a los maíces criollos o de polinización libre. De esta forma, los estudios que abordan en El Salvador temas nutricionales relacionados a maíces criollos suelen ser mucho más escasos. ${ }^{4}$

En virtud de la importancia del maíz para la dieta de los salvadoreños y a una ausencia de estudios sobre maíces nativos, el presente trabajo tiene como objetivo analizar aspectos 
nutricionales de seis maíces criollos en E1 Salvador. Específicamente, el presente texto se centra en identificar el contenido de proteína, hierro y zinc de estos materiales genéticos. De forma adicional y para efectos comparativos, se incluye en el siguiente análisis el testigo de maíz hibrido comercial Dekalb 390. A su vez, se explican los materiales y métodos utilizados. Posteriormente, se muestran y discuten los resultados encontrados, para finalmente delinear conclusiones derivadas del estudio.

\section{Materiales y Métodos}

Originalmente, durante el año 2013 fueron recolectadas muestras de seis maíces criollos en varias localidades del país, según información presentada en el Cuadro n. ${ }^{\circ} 1$. Estas variedades fueron Negro (negrito), Taberón, Olote Rosado, Ulupilse, Sapo y Chalatenango. Las mencionadas variedades fueron recogidas en localidades que presentan precipitaciones anuales de entre 1700 $\mathrm{mm}$ - $2122 \mathrm{~mm}$. En forma similar, todos los lugares donde fueron colectados los tipos de maíz presentan un clima tropical. Por su parte, en estas variedades fueron identificadas características fenotípicas de al menos cinco razas de maíces mexicanas, siendo predominante la raza tuxpeña, tepecintle y vandeño. Existía a su vez, de forma marginal, maíces de raza zapalote y cónico.

Las muestras descritas fueron sometidas entre los años 2013-2014 a un proceso de incremento, saneamiento y mejoramiento por medio de selección masal estratificada y selección masal recurrente en las instalaciones de la Escuela Nacional de Agricultura de El Salvador (L $13^{\circ} 47^{\prime} 57.85 \mathrm{LN} \mathrm{89} 9^{\circ} 4^{\prime} 5.37$ ) con altura de 459 msnm. Para el mejoramiento y saneamiento de las variedades de maíz criollo fueron montadas parcelas de 3,500 metros cuadrados en la Escuela Nacional de Agricultura, las que fueron cultivadas con labranza mínima. Los surcos tuvieron un espaciamiento de 80 centímetros entre ellos, con un espacio de 20 centímetros por postura. Se realizaron tres fertilizaciones en las parcelas, diferenciándose únicamente los niveles de nitrógeno para los maíces criollos. De esa forma, a estos seis tipos de maíz nativo le fue aplicado un nivel total de

\section{Cuadro n. ${ }^{\circ} 1$}

Información sobre las regiones agrícolas de donde provienen maíces criollos estudiados

\begin{tabular}{l|c|c|c|c}
\hline \multirow{2}{*}{ Tipo de maíz } & Ubicación de colecta & Precipitación anual aproximada mm & \multicolumn{2}{|c}{ Ubicación } \\
\cline { 3 - 5 } & & & Latitud & Longitud \\
\hline Negrito & Chalchuapa & 1700 & 13.989610 & -89.676919 \\
\hline Taberón & San Isidro Lajas Izalco & 2075 & 13.816667 & -89.583333 \\
\hline Olote Rosado & Guaymango & 2022 & 13.748419 & -89.845235 \\
\hline Ulupilse & Guaymango & 2022 & 13.748419 & -89.845235 \\
\hline Sapo & Arambala & 2007 & 13.920343 & -88.132799 \\
\hline Chalatenango & Chalatenango & 2122 & 14.039460 & -88.941434 \\
\hline
\end{tabular}

Fuente: Elaboración propia. 
$117 \mathrm{~kg}$ de nitrógeno por hectárea. En el caso del híbrido DK390 fueron aplicados $180 \mathrm{~kg}$ de nitrógeno por hectárea. Se utilizó una relación de N-P-K de 2:0.5:1. Para ellas, se valió los fertilizantes comerciales Nitro Xtend, sulfato de amonio y fórmula triple 15 (N-P-K). Los rastrojos de los cultivos anteriores se colocaron en el centro de los surcos para su descomposición y se estimó unos 0.5 a 0.75 $\mathrm{TN}$ de rastrojo/ha distribuidos en el terreno.

Las plantas extrañas al cultivo fueron manejadas manualmente, con el fin de evitar el uso de herbicidas y proteger el suelo de la erosión. Asimismo, no se aplicaron agroquímicos a los cultivos ya que esto nos permitiría determinar qué variedades eran más susceptibles a plagas y enfermedades y hacer una mejor selección de plantas.

Posteriormente, una vez las plantas alcanzaron su madurez fisiológica, se realizó una dobla de las mazorcas por dos motivos: evitar que el agua lluvia provocara pudrición de las mazorcas y para acelerar el sacado del grano. Cuando se consideraba que existía la humedad adecuada de grano, fueron seleccionadas al azar muestras de $1.0 \mathrm{~kg}$ de los diferentes maíces criollos mencionados y del híbrido comparativo. Estas muestras fueron enviadas al Laboratorio de Química Agrícola del Centro Nacional de Tecnología Agropecuaria y Forestal (CENTA), dependiente del Ministerio de Agricultura de E1 Salvador. En este laboratorio, se realizó el análisis bromatológico de los maíces seleccionados utilizando el método de fluorescencia de rayos X. De esta forma, se realizaría el análisis bromatológico de los seis maíces criollos y de la semilla híbrida comercial Dekalb DK390.

\section{Resultados y discusión}

Los resultados son presentados en el Cuadro 2. En primer lugar, es destacable que todos los maíces criollos analizados tienen contenido de nutrientes similar al híbrido DK390. Pese a ello, todos los maíces criollos analizados superan al híbrido comercial en contenido de hierro. En relación con el contenido de proteína y zinc, el maíz DK390 presenta los segundos peores índices, levemente detrás del maíz Ulupilse y Chalatenango, respectivamente. Estos resultados modestos del testigo híbrido son destacables, puesto a que los maíces híbridos de la línea DK son considerados por profesionales locales como un maíz de buena calidad y con potencial de alto rendimiento (Ayala y Waquil, 2019). En ese sentido, esta línea comercial de maíz es recomendada por extensionistas rurales para que sea plantada por agricultores con posibilidad de costear esta semilla; especialmente para agricultores que producen maíz con fines comerciales (Ayala y Waquil, 2019). Pese a esta buena reputación, el maíz DK390 no presentó índices marcadamente superiores a los demás maíces criollos analizados.

La variedad criolla Taberón (también conocido como Maizón o Tabero) es la que presentó mayor contenido de proteína. El mismo ha sido cultivado al menos desde el siglo XX en varias partes del territorio salvadoreño, siendo utilizada para consumo humano y como forraje. E1 segundo mejor maíz en porcentaje de proteína fue el maíz Negro (negrito) que no es ampliamente cultivado e incluso consumido en el país. El maíz negrito es utilizado primordialmente para la preparación de la bebida típica fermentada llamada Atol chuco, y no para el consumo en 


\section{Cuadro n. ${ }^{\circ}$ 2:}

Resultados de análisis bromatológico

\begin{tabular}{l|c|c|c}
\hline \multicolumn{1}{c|}{ Maíz } & \% de proteína & Hierro mg.kg. & Zinc. mg.kg. \\
\hline Híbrido DK390 & 8,71 & 13,15 & 15,95 \\
\hline Negrito & 10,25 & 18,57 & 21,73 \\
\hline Taberón & 10,37 & 16,95 & 18,75 \\
\hline Olote Rosado & 9,94 & 16,85 & 16,75 \\
\hline Ulupilse & 8,5 & 17,1 & 24,27 \\
\hline Sapo & 8,74 & 16,2 & 19,25 \\
\hline Chalatenango & 10,13 & 15,6 & 15,8 \\
\hline Media & 9,52 & 16,34 & 18,92 \\
\hline
\end{tabular}

Fuente: Elaboración propia con base en análisis bromatológico. Unidades: Proteína (porcentaje), Hierro (mg.kg) y Zinc (mg. kg).

tortillas. No obstante, este maíz suele ser más costoso que cualquier otra variedad de maíz blanco en el mercado nacional. Este precio se debe a que existe poca oferta, el número de productores es reducido y a que el mismo debe ser cultivado fuera de la época invernal (que comienza usualmente en mayo en El Salvador), con el objetivo de mantener su pureza genética. En términos generales, pese a que los maíces con mejores índices proteicos son criollos, según las estadísticas oficiales más recientes, la utilización de este maíz nativo es baja en la producción a nivel nacional (MINEC, 2009).

Estos porcentajes de proteína encontrados en los maíces criollos en El Salvador son consistentes con otros estudios similares realizados internacionalmente. En tal sentido, Vera-Guzmán, Chávez y Carrillo (2012) colectaron 70 muestras de poblaciones de maíz en Oaxaca, y analizaron su contenido de proteína, triptófano y lisina. En este estudio se encontraron maíces criollos con un porcentaje de proteína (base húmeda) que oscila entre
$8,7 \%$ hasta el $14,9 \%$, lo que representa indicadores superiores a los encontrados en El Salvador. De forma similar, Mbuya et al. (2011) analizó en El Congo el contenido de proteínas y aminoácidos esenciales en variedades de maíz de alta calidad proteica y maíz normal. Estos autores reportaron un porcentaje de proteína cruda del 10,07\% para la variedad QPM-SR-SYNTH y de 9,76\% para la variedad QPM Longe 5 (Ibídem, 2011). Por su parte, los maíces criollos analizados en el mencionado estudio poseían un porcentaje de proteína que oscilaba entre el 10,07\% al 12,09\%; siendo que una variedad local presentó un porcentaje de proteína del 11,64\%. Estos resultados abren la puerta para introducir el debate sobre el contenido proteico del maíz criollo, comercial (mejorado, certificado, comercial, etc.) y maíz de alta calidad proteica. Para el caso de estudio de El Salvador, el maíz comercial DK390 posee el segundo menor contenido de proteína de las muestras analizadas $(8,71 \%)$. En ese sentido, el costo adicional 
que implica la adquisición de esta semilla no se vería compensado por el contenido proteico del mismo. En El Salvador, algunos maíces criollos presentan contenidos altos de proteína, llegando a valores de más del 10\%. Paradójicamente, determinados tipos de maíz criollo pueden presentar índices de contenido proteico superior a las variedades mejoradas de maíz de alta calidad proteica (QPM), como algunos de los analizados por Mbuya et al. (2011).

En términos de contenido de hierro, el maíz que presentó mejor índice fue el maíz negrito con $18.57 \mathrm{mg} . \mathrm{kg}$. En segundo lugar, se ubicó el maíz Ulupilse con 17.1 mg.kg. En términos comparativos, Queiroz et al. (2011) analizó en Brasil muestras de 22 líneas de maíces, reportando valores entre 12.2-36.7 mg.kg; teniendo como media 24.2. Estos valores son sustancialmente más elevados a los reportados en el presente estudio, cuya media asciende a 19.07 mg.kg. De forma adicional, Martínez, Ortíz y Raigón (2017) analizaron 50 accesiones de diversos tipos de maíz en Cuba. Este estudio reportó valores mínimos de hierro de 4 mg.kg y máximos de $39.1 \mathrm{mg} . \mathrm{kg}$; con una media de $12.7 \mathrm{mg} . \mathrm{kg}$. Esta media es inferior a la encontrada en el presente estudio en El Salvador. Pese a ello, los resultados reportados por Martínez, Ortíz y Raigón (2017) muestran una gran dispersión en los índices de hierro. A su vez, Rajbhandari y Subedi (2013); reportaron valores de hierro entre 17-22 mg.kg para muestras de maíz en Nepal, lo que representa valores levemente superiores a los encontrados en El Salvador. Estos autores compararon los mencionados índices de hierro en maíz nepalí con maíz proveniente de Estados Unidos y de África, siendo que el maíz nepalí muestra valores de hierro similar al estadounidense y levemente superior en el caso africano (Rajbhandari \& Subedi, 2013). Por su parte, Loyola et al. (2018) abordaron una vertiente diferente a la hora de analizar el contenido de hierro en maíz, siendo que estas autoras se centraron en el contenido de este micronutriente específicamente en una elaboración alimenticia típica del maíz blanco: la tortilla nixtamalizada. En este estudio realizado en México se reportan valores de hierro de entre 5.3-10.01 mg de hierro por cada kilogramo de tortilla (Loyola et al., 2018).

En relación con el contenido de zinc, el maíz Ulupilse fue el que mejor desempeño tuvo (24.27 mg.kg), seguido por el maíz negrito (21.73 mg.kg). El maíz tipo Chalatenango fue el peor evaluado en esta característica, seguido muy de cerca por el maíz híbrido DK390. Nuevamente Queiroz et al. (2011) encontró valores superiores a la media salvadoreña (18.92 mg.kg), reportando una media para el caso brasileño de $27.2 \mathrm{mg} . \mathrm{kg}$ en contenido de zinc. Esta misma tendencia fue encontrada por Martínez, Ortíz y Raigón (2017); al reportar una media de 23.6 mg.kg en contenido de zinc de las 50 muestras que ellos analizaron para el caso cubano.

En el presente análisis bromatológico para los maíces salvadoreños, no fue posible identificar ningún tipo de maíz que destaque marcadamente de los otros en contenido de proteína, hierro y zinc; como lo muestra la Figura 1. Así, por ejemplo, la variedad criolla Ulupilse, que reportó peor porcentaje de proteína es el que muestra mejor desempeño en contenido de Zinc. 


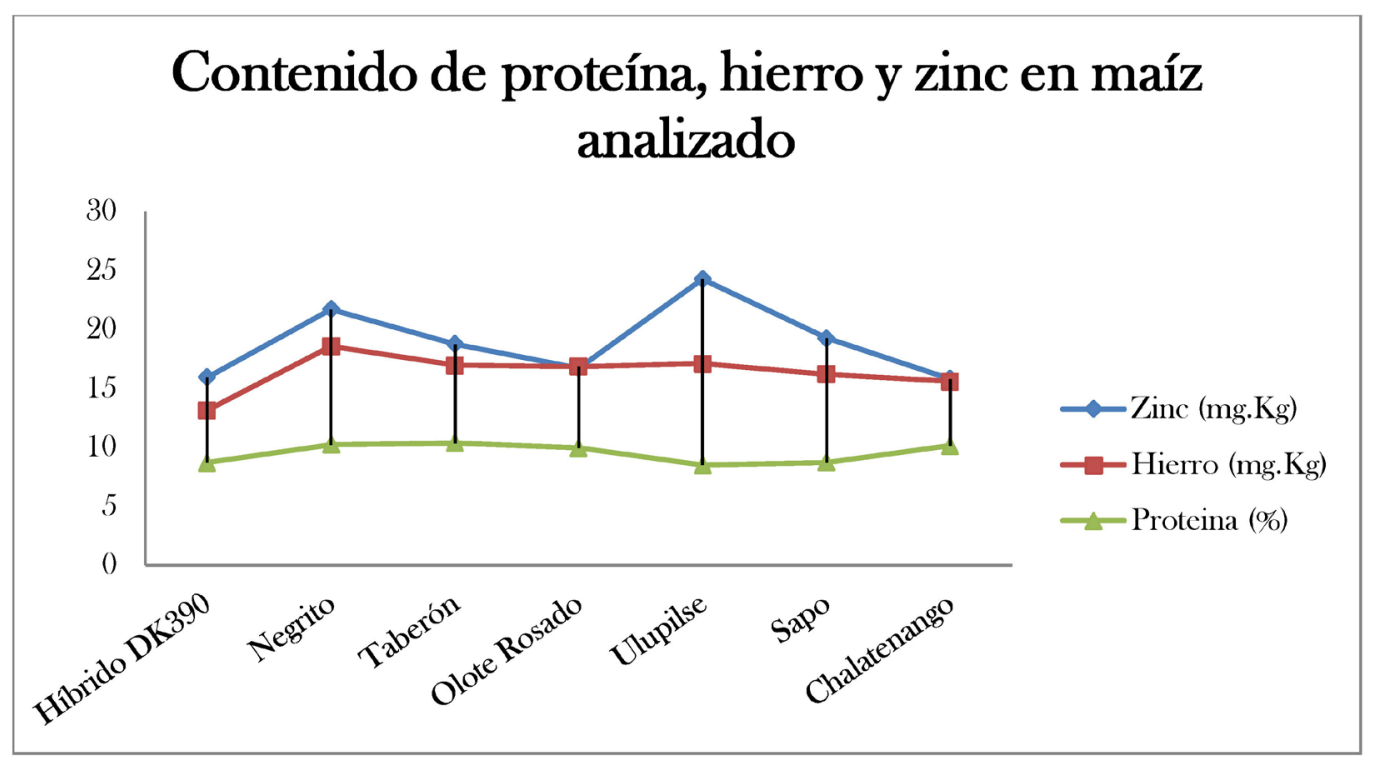

Figura $n .^{\circ}$ 1. Contenido de proteína hierro y zinc en diferentes tipos de maíz analizado. Unidades: Zinc (mg.Kg), hierro (mg.Kg) y proteína (\%). Fuente: Elaboración propia.

Finalmente, abrir el debate sobre contenido nutricional del maíz en El Salvador presenta un importante avance, ya que existe generalmente una deriva productivista en el país, donde se prima el incremento en la producción del cereal, sin tomar usualmente en consideración aspectos sobre la calidad de los alimentos. ${ }^{5}$ No obstante, además del contenido de nutrientes, es necesario avanzar en investigaciones que apunten hacia la biodisponibilidad y la absorción de los mismos; temas aún relegados en el caso de la investigación en El Salvador.

\section{Conclusiones}

Siendo que el maíz tiene una importancia fundamental en Mesoamérica y en El Salvador, cada vez resulta más evidente que el estudio y la investigación de este cereal se debe de hacer desde enfoques que vayan más allá de la producción total del maíz por unidad de tierra. Siendo así, aspectos nutricionales se erigen como un tema fundamental para una mejor comprensión de la cultura del maíz en El Salvador. La creciente importancia de aspectos nutritivos relacionados a este cereal se ve reflejado en la investigación pública, pudiendo identificarse el desarrollo y validación de maíces de alta calidad proteica, como lo son los maíces Platino, Oro Blanco (CENTA, 2008) y Protemás (CENTA, 2008b); liberados por el Centro Nacional de Tecnología Agropecuaria y Forestal (CENTA). Pese a ello, la investigación para el desarrollo de maíz de alta calidad proteica está usualmente focalizada en los maíces híbridos, dejando de lado los maíces criollos. De tal suerte, textos como el presentado cobran particular importancia al tratar temas sobre el fitomejoramiento del maíz utilizando materiales genéticos nativos. 
Con ello, los resultados alcanzados reportan que aunque el maíz híbrido suele ser preferido por agrónomos y algunos órganos públicos, no ha presentado índices nutricionales superiores a las variedades criollas estudiadas. En realidad, el testigo híbrido presentó el peor contenido de hierro, y el segundo peor contenido de zinc y proteína en los materiales genéticos evaluados. Estos resultados cobran particular importancia ya que el híbrido DK390 suele ser visto por extensionistas rurales salvadoreños como un maíz de buena calidad, con lo que el mismo es recomendado para que sea plantado por agricultores con la posibilidad de costear la compra de este insumo agrícola.

Adicionalmente, los resultados reportados hacen necesario analizar en estudios posteriores los índices nutricionales de otros tipos de maíces comerciales, especialmente aquellos que son ampliamente comercializados en el país o los que son directa e indirectamente subsidiados por el Gobierno salvadoreño. De esa forma, sería particularmente pertinente realizar evaluaciones bromatológicas sobre el maíz híbrido H-59, mismo que es ampliamente subsidiado por el Estado salvadoreño y donado en paquetes agrícolas a pequeños agricultores. Asimismo, evaluar las variedades de polinización libre Santa Rosa y Pasaquina, que han sido desarrolladas, validadas y liberadas por CENTA, sería igualmente valioso. La inclusión de aspectos adicionales como absorción de nutrientes o biodisponibilidad serían asimismo positivos.

Finalmente, los resultados encontrados invitarían a continuar la investigación, a nivel técnico y social, sobre los maíces criollos en El Salvador. Los mismos suelen tener requerimientos nutricionales menores, están más adaptados a las características agronómicas salvadoreñas y pueden ser reproducidos por el propio agricultor al guardar semilla. Esta práctica milenaria del resguardo y selección de semilla permitiría utilizar una mayor cantidad de insumos propios de la misma parcela agrícola, lo que traería consigo una disminución en los costos de producción del maíz.

\section{Bibliografía}

Ayala Durán, C. (2018). Sistema agroalimentario del maíz blanco en Ciudad Arce, municipio de El Salvador, tesis doctoral, Universidade Federal do Rio Grande do Sul, Porto Alegre, Brasil.

Ayala Durán, C., De Andrade Miguel, L. (2016). Acumulación de riqueza: sistemas agrarios en la región norte del departamento de La Libertad, El Salvador. Ágora, 18(2), 134-149. doi: 10.17058/ agora.v18i2.8457

Ayala Durán, C., \& Waquil, P. D. (2019). Agricultura orgánica, maíz criollo y extensión rural: percepciones de profesionales salvadoreños. Realidad y Reflexión, 49(1), 106-126. doi: 10.5377/ryr.v49i49.8068

Centro Nacional de Tecnología Agropecuaria y Forestal (CENTA). (2002). Híbrido de Maíz HQ-61. Boletín Técnico n. ${ }^{\circ}$. San Andrés, El Salvador: Autor.

Centro Nacional de Tecnología Agropecuaria y Forestal (CENTA). (2008). Hibridos de maiz de alta calidad proteica: Oro Blanco y Platino. Boletín Técnico 20. San Andrés, E1 Salvador: Autor. 
Centro Nacional de Tecnología Agropecuaria y Forestal (CENTA). (2008b). Protemás: Variedad de Maíz de Alta Calidad Proteica. Boletín Técnico 29. San Andrés, El Salvador: Autor.

Centro Nacional de Tecnología Agropecuaria y Forestal (CENTA). (2016). CENTA H-CAS: híbrido de maíz de alta calidad proteíca para nutrir a El Salvador. San Andrés, El Salvador: Autor.

Delgado, C., Díaz, J., Díaz, C., Escalante, C., Escobar, K., Estrada, J., y Fermán, J. (2015). Evaluación de las características físicas y químicas de tres variedades (Taberón, Mexicano, Platino) de maíz elotero (Zea Mays), tesis de grado, Escuela Nacional de Agricultura, El Salvador.

Loyola Jiménez, M., Sotelo, I., y Rubio, C. (2018). Determinación de bierro en tortillas de maiz nixtamalizado por el método espectrofotométrico $U V$-Visble con fenantrolina. Trabajos ganadores del XXIII Concurso Universitario: Feria de Ciencias, la tecnología y la innovación. Ciudad de México. Disponible en: http:// www.feriadelasciencias.unam.mx/anteriores/ feria23/feria139_01_determinacion_de_hierro_ en_tortillas_de_maiz_nixta.pdf. Consultado: 20/10/2017.

Machado, A., Redin, C., Ayala Durán, C., Mezzonato, D., Zúñiga, M., Biehl, R., Dal Soglio, F. (2016). SEGURANÇA ALIMENTAR E NUTRICIONAL E A SUSTENTABILIDADE. En R. Kubo \& F. Dal Soglio, SEAD. Desenvolvimento, agricultura e sustentabilidade (pp. 93-114). Porto Alegre: Universidade Federal do Rio Grande do Sul.
Martínez Cruz, M., Ortiz Pérez, R., \& Raigón, M. D. (2017). Contenido de fósforo, potasio, zinc, hierro, sodio, calcio y magnesio, análisis de su variabilidad en accesiones cubanas de maíz. Cultivos Tropicales, 38(1), 92-101.

Mayozer, M., y Roudart, L. (2010). História das agriculturas no mundo. Do neolítico à crise contemporânea. 1 Ed. Brasilia: UNESP.

Mbuya, K., Nkongolo, K. K., \& KalonjiMbuyi, A. (2011). Nutritional analysis of quality protein maize varieties selected for agronomic characteristics in a breeding program. International Journal of Plant Breeding and Genetics, 5(4), 317-327. doi: 10.3923/ ijpbg.2011.317.327.

Menchú, M. T., y Méndez, H. (2011). Análisis de la Situación Alimentaria en El Salvador. Guatemala: INCAP.

Ministerio de Economía de El Salvador (MINEC). (2009). IV Censo Agropecuario 20072008. Resultados Nacionales. San Salvador: Autor.

Rajbhandari, A., \& Subedi, T. (2013). Spectrophotometric Determination of Total Iron in Rice and Maize Samples. Scientific World, 11(11), 101-104. doi: 10.3126/sw.v11i11.8562.

Vera-Guzmán, A. M., Chávez-Servia, J. L., Carrillo-Rodríguez, J. C. (2012). Proteína, lisina y triptófano en poblaciones nativas de maíz mixteco. Revista fitotecnia mexicana, 35 (SPE5), 07-13. 
Queiroz, V. A. V., Guimarães, P. E. D. O., Queiroz, L. R., Guedes, E. D. O., Vasconcelos, V. D. B., Guimarães, L. J., ... \& Schaffert, R. E. (2011). Iron and zinc availability in maize lines. Food Science and Technology, 31(3), 577-583. doi: 10.1590/S0101-20612011000300005.

\section{Notas al final}

1 Algunas de las conclusiones señaladas por Ayala y Miguel (2016) para La Libertad, serían igualmente válidas para buena parte del territorio salvadoreño.

2 Con ello, temas como calidad, nutrientes o residuos de agro tóxico en el maíz, son factores poco abordados. Este último cobraría especial relevancia en El Salvador, dado que, según estadísticas oficiales, la gran mayoría de maíz cultivado en este país es híbrido, utilizando agrotóxicos (MINEC, 2009).
3 Según la Cumbre Mundial sobre Alimentación de 1996, existe seguridad alimentaria cuando las personas tienen en todo momento, acceso físico y económico a alimentos seguros, nutritivos y suficientes para satisfacer sus necesidades dietéticas y preferencias alimentarias, a fin de llevar una vida activa y sana. Para mayor información, consultar el recorrido histórico elaborado por Machado et al. (2016).

$4 \mathrm{Si}$ bien se tiene conocimiento de algunos estudios relevantes como el de Delgado et al. 2015.

5 Con la destacable excepción de la investigación realizada desde la esfera pública sobre maíz de alta calidad proteica. 